\title{
Correction to: Ablative Treatment of Breast Cancer; Are We There Yet?
}

\section{David R Brenin ${ }^{1}$}

Published online: 18 June 2019

(C) Springer Science+Business Media, LLC, part of Springer Nature 2019

\section{Correction to: Curr Breast Cancer Rep (2019) https://doi.org/10.1007/s12609-019-0307-1}

The original version of this article unfortunately contained a mistake in the article title. The captured title was "Local-Regional Evaluation and Therapy (D Euhus, Section Editor)" instead of "Ablative Treatment of Breast Cancer; Are We There Yet?"

The original article has been corrected.

Pulisher's Note Springer Nature remains neutral with regard to jurisdictional claims in published maps and institutional affiliations

The online version of the original article can be found at https://doi.org/ 10.1007/s12609-019-0307-1

David R Brenin

drb8x@virginia.edu

1 Department of Surgery, University of Virginia Health System, P.O. Box 800709, Charlottesville, VA 22908-0709, USA 